\title{
Correspondence
}

\section{Supervision registers}

Sir: I would like to express my concern with regard to the use of supervision registers in the light of a recent experience of trying to place one of my patients on the register.

At one of our recent multidisciplinary reviews of a day patient within the rehabilitation service we discussed this man's vulnerabilities and particularly whether he should be included on a supervision register. This patient is shortly to be discharged to a different day care facility within another health authority. In the past he has deteriorated and relapsed at time of change and during these times he is more likely to be both verbally and physically aggressive to others. He has, on one occasion, made a serious attack on a fellow resident. In view of this we agreed to include him on the supervision register during the time of change. This decision would be reviewed once he was settled within his new placement.

This patient attends the day services and lives in supported accommodation run by a voluntary sector organisation. When we informed this organisation of the intent to place the patient on the supervision register we were told that if he were on the register his placement would be in jeopardy and he would be given notice to quit.

Clearly in this situation placing this individual on a supervision register was actually increasing his risk of relapse as he was being made homeless by virtue of being on the register. I find this situation very worrying and while locally I am endeavouring to resolve the situation, I am concerned that this may be an issue that other people are grappling with nationally. If this is the case then I do feel we need to address this within the College and in particular in discussions with the Department of Health.

J. D. QuinN, Northumberland Mental Health NHS Trust, St George's Hospital, Morpeth, Northumberland NE61 2NU

Sir: It is important to detail the updated position on the implementation of supervision registers locally, the agreement on which was the subject of an article by McCarthy et al (Psychiatric Bulletin, April 1995, 19, 195-199).

Following the agreement of local guidance between the Health Commission and our three local provider Trusts, discussions took place with the Department of Health and NHS Executive. They were concerned to ensure that such guidance was within the spirit of HSG(94)5 and did not undermine national policy. We assure them that we sought a practical local approach and demonstrated that the tiered approach to the care programme approach and supervision registers met the requirements of national guidance. In the 1995/96 contracts we have made explicit that nothing in this local guidance is intended to restrict the clinial freedom of any local psychiatrist to add a patient to the register should they consider it necessary albeit that they do not meet the locally agreed criteria.

In the light of these assurances, the Department of Health and the Executive were able to agree that our local approach was, indeed, practical in an area of extremely high psychiatric morbidity. It is the view of the Health Commission that such a collaborative approach between purchasers and providers is the best way to ensure effective implementation and the development of best practice.

ToNy Goss, Contract Manager, Mental Health \& Substance Misuse, Lambeth Southwark \& Lewisham Health Commission, 1 Lower Marsh, London SE1 7NT

\section{Supervised After-care Bill}

Sir: The Supervised After-care Bill which was published on 15 February 1995 is a disappointing Bill. It is designed to introduce a new "framework for the supervision of mentally disordered patients in England and Wales aged 16 years or over" (HMSO, 1995). It empowers responsible medical officials to require a patient to reside at a specified place or to attend for medical treatment, occupation, 